\title{
How Game Addiction Rates and Related Psychosocial Risk Factors Change Within 2-Years: A Follow-Up Study
}

\author{
Erkan Baysak $^{1 凶}$, Fatma Duygu Kaya Yertutanol ${ }^{2}$, Ilker Dalğar ${ }^{3}$, and Selçuk Candansayar ${ }^{4}$ \\ ${ }^{1}$ Department of Psychiatry, Haydarpasa Numune Training and Research Hospital, Istanbul, Turkey \\ ${ }^{2}$ Department of Psychology, Uskudar University, Istanbul, Turkey \\ ${ }^{3}$ Department of Psychology, Middle East Technical University, Ankara, Turkey \\ ${ }^{4}$ Department of Psychiatry, Gazi University Faculty of Medicine, Ankara, Turkey
}

Objective Prospective data of risky online gamers in Turkey is missing. Therefore, we aimed to investigate the change in gaming behaviors and addiction rates of Travian players within two years to search diagnostic stability of internet gaming disorder and some psychosocial risk factors.

Methods 110 responders completed the whole questionnaire package including 21-item Game Addiction Scale (GAS), Satisfaction with Life Scale (SLS), Rosenberg Self-Esteem Scale (RSES), and Multi-dimensional Scale of Perceived Social Support (MSPSS). A hierarchical linear modeling approach was followed to test the linear change in game addiction scores of the participants from 2013 to 2015.

Results GAS scores of gamers significantly decreased within two years $(p=0.026)$. MSPSS scores significantly and negatively associated with GAS scores $(\mathrm{p}<0.001)$ and the negative association of time remained significant $(\mathrm{p}=0.035)$. Decrement in the MSPSS scores in two years was associated with increment in GAS scores. 9 (90\%) of 10 participants with internet gaming disorder according to monothetic format and 26 (52\%) of 50 participants with internet gaming disorder according to polythetic format were found to not to meet the diagnosis in the follow-up. 33 out of all participants reported that they were not playing any online games for at least last 6 months.

Conclusion Social support seems to be a protective factor for game addiction and diagnosis of internet gaming disorder has low temporal stability among Travian players in Turkey.

Psychiatry Investig 2018;15(10):984-990

Key Words Online game addiction, Internet gaming disorder, Social support, Self-esteem, Life satisfaction, Diagnostic stability.

\section{INTRODUCTION}

While the concept of gaming addiction is known for a long time and referred to as online game addiction, video game addiction, and excessive/problematic/pathological online gaming, it has been coined recently as internet gaming disorder (IGD) in DSM-5 that is substantially based on gambling disorder criteria and further research on the topic is recommended. ${ }^{1}$ Related search is encouraged by national and international institutions to reveal different aspects of the problem such as sociodemographic features of the gamers, game ad-

\footnotetext{
Received: June 7, 2018 Revised: August 4, 2018

Accepted: August 16, 2018

$\triangle$ Correspondence: Erkan Baysak, MD

Department of Psychiatry, Haydarpasa Numune Training and Research Hospital, Selimiye Mahallesi, Tibbiye Cad. No:23, 34668, Uskudar/Istanbul, Turkey Tel: +90 (216) 54232 32, Fax: +90 (216) 3360565

E-mail: erkanbaysak@gmail.com

(a) This is an Open Access article distributed under the terms of the Creative Commons Attribution Non-Commercial License (https://creativecommons.org/licenses/bync/4.0) which permits unrestricted non-commercial use, distribution, and reproduction in any medium, provided the original work is properly cited.
}

diction rates among populations, and negative consequences of online gaming. There is growing number of studies which aim to clarify protective and risk factors for online gaming such as self-esteem, social support, life satisfaction, loneliness, and psychiatric disorders including social phobia, attention deficiency hyperactivity disorder, anxiety, and depression. ${ }^{2}$

Although various aspects of IGD are being investigated by the researchers on the field, primary studies focus on the validation of the proposed diagnostic criteria of it. The addiction based criteria of IGD seems to involve some concerns in terms of accurate conceptualization of the problem. ${ }^{3}$ Beside this, episodic course of excessive online gaming which leads to a low temporal diagnostic stability is criticized among researchers in the field. It is being argued that excessive online gaming can be a transient behavior that doesn't indicate an addiction and presence of negative consequences of excessive gaming is the key factor for diagnosis of addiction. ${ }^{4}$ Therefore, it seems that long term follow-up of the gamers along with assessing the negative impact of gaming is crucial to distinguish the pathological cases from non-pathological ones. The 
need for long-term studies entailed researchers to investigate diagnostic stability, predictive and protective factors of IGD via prospective methods $s^{5}$ but it is inevitable that more prospective studies are needed.

It is well known that online gaming is becoming a remarkable problem worldwide and Turkey in particular is a rapidly growing market for gaming industry. According to Global Online Gaming Market 2014 report of yStats.com, over 20 million people in Turkey play games online regularly, ${ }^{6}$ and according to Newzoo there are 9.8 million Turkish massively multiplayer online game (MMOG) players $80 \%$ of whom under $35 .^{7}$ This statistical data is important as it may indicate a problematic online gaming and/or a possible addiction among this young population. On the other hand, although there are several studies investigating the relationship of IGD and related psychosocial factors worldwide, the social and psychological reflection of IGD is substantially missing in Turkey which makes the topic even more significant. In most of the limited studies in Turkey that evaluate internet use and gaming, the participants are adolescents or young adults from general population but not online gamers. ${ }^{8-10}$ Other limited number of studies that were conducted with online gamers investigated some factors like game motivation and self-efficacy $^{11,12}$ but comprehensive prospective studies that evaluate diagnostic stability of IGD and related psychosocial factors are not available in Turkish literature.

We have recently evaluated the reliability and validity of "Game Addiction Scale" (GAS) that was developed by Lemmens et al. ${ }^{13}$ as an instrument to assess online game addiction, in a sample of 726 Travian-a massively multiplayer online game-players in Turkey. ${ }^{14}$ We also reported the sociodemographic data ${ }^{15}$ and addiction rates of the participants. The results revealed that $11 \%$ of Travian players met addiction criteria when monothetic format of GAS was used and this rate was higher than other studies in literature. ${ }^{16}$

However, prospective data of these risky gamers in Turkey is missing due to lack of studies in this field. Therefore, we contacted the same sample of Travian players after two years to investigate the change in addiction rates to search diagnostic stability of IGD and some psychosocial risk factors such as self-esteem, perceived social support, and life satisfaction. There are several studies that point out a relationship between addiction and self-esteem, perceived social support, and life satisfaction. ${ }^{17-20}$ We think that these variables might be important because escaping from reality, socializing, competition and achievement are core motivations for gaming ${ }^{21}$ and games serve as a setting that can change the psychosocial perceptions of the individuals. Therefore, aforementioned psychosocial factors seem to be risk factors for online gaming. The present study is of great importance in the context of
IGD for being the first online and prospective study in Turkey. Since IGD is not an official disorder, in the rest of the text, we used this term in order to indicate not a clinical diagnosis but a condition where online gaming is problematic and potential addiction is present.

\section{METHODS}

\section{Procedure}

This is a two-year prospective study with a single followup. In order to contact with Travian players, an account was created via Travian Turkish server and an invitation message was sent to the union leaders or to the gamers directly in year 2013. The aim of the study was explained to participants and they were asked to fill the online questionnaire package after giving informed written consent. The study was conducted via SurveyMonkey and the data collection was limited to three months. The same invitation message was sent two more times within this period to increase the participation rates. Repetitive entrance to system was avoided by preventing multiple responses per person within study interval.

A similar procedure was followed via sending invitation e-mails to same participants who provided their e-mail addresses after two-year interval and they were asked to fill the questionnaire package in year 2015.

\section{Measures}

\section{Game addiction Scale}

The scale including 21-item long form and 7-item short form was developed by Lemmens et al. ${ }^{13}$ GAS is a 5-point Likert scale which covers seven criteria including withdrawal, salience, tolerance, relapse, conflict, problems and mood modification. ${ }^{13}$ Turkish adaptations of the scales were performed by Baysak et al. ${ }^{14}$ We have recently reported that both 21-item (Cronbach's $\alpha=0.96$ ) and 7-item versions (Cronbach's $\alpha=0.88$ ) of the GAS is valid and reliable among Turkish sample. ${ }^{14}$

\section{Satisfaction with Life Scale (SLS)}

This 7-point scale that ranges from 7 strongly agree to 1 strongly disagree was developed by Diener et al. ${ }^{22}$ and assess satisfaction with the respondent's life as a whole. The total score increase as the life satisfaction of the respondent increase. The Turkish adaptation of the scale was performed by Köker. $^{23}$

\section{Rosenberg Self-Esteem Scale (RSES)}

Morris Rosenberg developed the scale in 1965. The 10 items are answered on a four point scale ranging from strongly agree to strongly disagree. The Turkish adaptation of the scale was 
performed by Çuhadaroğlu. ${ }^{24}$

\section{Multi-dimensional Scale of Perceived Social Support (MSPSS)}

The scale was developed by Zimet et al. ${ }^{25}$ to measure perceptions of support from 3 sources: family, friends, and a significant other. This self-report questionnaire contains twelve items rated on a seven-point Likert-type scale with scores ranging from 'very strongly disagree' to 'very strongly agree. Turkish adaptation of the scale was performed by Eker and Arkar. ${ }^{26}$

Same questionnaire package including 21-item GAS (that also cover 7-item GAS short form), Satisfaction with Life Scale (SLS), Rosenberg Self-Esteem Scale (RSES) short form, and Multi-dimensional Scale of Perceived Social Support (MSPSS) were given to the participants in both assessments. In the follow-up, participants were asked whether they still play any online games. Thirty three participants out of 110 gamers, who reported that they hadn't been playing any online games for at least last 6 months, were not given GAS considering the time limitation of the questionnaire that cover only "last six months".

Sociodemographic data such as age, gender, monthly income, and game playing characteristics such as playing frequency and duration of each game session were collected only in the first assessment.

\section{Statistical analysis}

A hierarchical linear modeling approach was followed to test the linear change in game addiction scores of the online gamers from 2013 to 2015 . The full model was tested in two steps via HLM 7 Software. ${ }^{27}$ In the first step, unconditional growth model was performed by only adding time into the equation to test the change in online game addiction from 2013 to 2015. At the second step the proposed predictors were added into the equation to test whether any predictor uniquely associated with online game addiction. The robust estimations were evaluated for the significance of the associations between variables.

\section{Ethics}

The study procedures were carried out in accordance with the Declaration of Helsinki. The Institutional Review Board of the (Gazi University, Faculty of Medicine) approved the study (Approval Number: 18.06.15/06). All subjects were informed about the study and all provided informed consent.

\section{RESULTS}

\section{Participants}

745 people out of 1,763 who clicked the study link complet- ed all questionnaires in the first stage of the study in 2013. In the follow-up, in 2015, 133 gamers responded to the e-mail invitation and 110 of them completed the whole questionnaire package, thus, data of 110 participants were analyzed in this study. $90 \%(\mathrm{n}=99)$ of the participants were male and 10\% $(\mathrm{n}=11)$ were female. Mean age was $30.75 \pm 9.68$ (male: $30.9 \pm$ 9.8, female: $30.4 \pm 9.4) .68 .2 \%(\mathrm{n}=75)$ of the participants had a university degree, $43.6 \%(n=48)$ of them were married and $62.7 \%(n=69)$ had a regular job. The details of sociodemographic variables are shown in Table 1.

\section{Travian gaming characteristics}

$54.5 \%(\mathrm{n}=60)$ of the participants reported that they spent money in the game and their monthly average expenditure was 41.2 TL (approximately $\$ 21.6$ at the time of data collection - 2013). Weekly time spent in the game was 42.5 hours and the average online gaming duration without giving a break was 9.4 hours. The gamers reported that they login the game

Table 1. Sociodemographic variables of the participants

\begin{tabular}{lc}
\hline \multicolumn{1}{c}{ Variables } & $\mathrm{N}(\%)$ \\
\hline \hline Gender & \\
Male & $99(90)$ \\
Female & $11(10)$ \\
Educational degree & \\
Primary school & $6(5)$ \\
High school & $17(15.5)$ \\
College & $75(68.2)$ \\
Master's or doctoral & $12(10.9)$ \\
Marital status & \\
Married & $48(43.6)$ \\
Single & $55(50.0)$ \\
Divorced, apart & $7(6.4)$ \\
Current job & \\
Student & $34(30.9)$ \\
Regular employee & $69(62.7)$ \\
Employed on occasion & $2(1.8)$ \\
Unemployed & $5(4.5)$ \\
Residence & \\
Alone & \\
With home mates & $12(10.9)$ \\
With parents, or family member & $18(16.3)$ \\
With spouse, children & $31(28.2)$ \\
Dormitory & $46(41.8)$ \\
Monthly income (TL) & $3(2.7)$ \\
Under $800^{\dagger}$ & \\
801-1500 & $5(4.5)$ \\
1501-3000 & $15(13.6)$ \\
Over 5000 & $48(43.6)$ \\
& $22(20.0)$ \\
USD: 19000 & $20(18.2)$ \\
\hline
\end{tabular}

*1 USD: 1.90 TL (in year 2013), ${ }^{\dagger} 800$ TL: Minimum net wage in Turkey in year 2013. TL: Turkish Lira 
Table 2. Gaming characteristics

\begin{tabular}{lcccc}
\hline \multicolumn{1}{c}{ Gaming characteristics } & Minimum & Maximum & Mean & SD \\
\hline Monthly average expenditure in the game (TL) & 1 & 250 & 41.2 & 47.6 \\
Weekly time spent in the game (hour) & 2 & 168 & 42.5 & 27.2 \\
Online gaming duration without giving a break (hour) & $0^{\dagger}$ & 168 & 9.4 & 19.2 \\
Daily number of logins & 1 & 500 & 13.5 & 47.3 \\
\hline
\end{tabular}

*only 60 participants, ${ }^{\dagger}$ less than 1 hour. TL: Turkish Lira, SD: standard deviation

Table 3. Mean scores of GAS, SLS, RSES, and MSPSS in 2013 and 2015

\begin{tabular}{lrrrrr}
\hline \multirow{2}{*}{ Scales } & \multicolumn{2}{c}{2013} & & \multicolumn{2}{c}{2015} \\
\cline { 2 - 3 } \cline { 5 - 6 } & Mean & \multicolumn{1}{c}{ SD } & & Mean & SD \\
\hline \hline GAS-21 & 56.45 & 20.14 & & 51.93 & 17.48 \\
SLS & 22.40 & 6.35 & & 20.37 & 6.97 \\
RSES & 31.62 & 5.59 & & 26.45 & 2.39 \\
MSPSS & 57.33 & 17.77 & & 56.75 & 17.99 \\
Family & 20.63 & 6.38 & & 20.28 & 7.09 \\
Friends & 20.66 & 6.82 & & 19.90 & 6.86 \\
Other & 16.03 & 9.40 & & 16.56 & 8.65 \\
\hline
\end{tabular}

GAS: Game addiction Scale, SLS: Satisfaction with Life Scale, RSES: Rosenberg Self-Esteem Scale, MSPSS: Multi-dimensional Scale of Perceived Social Support, SD: standard deviation

13.5 times a day. The details of gaming characteristics of the participants are shown in Table 2.

\section{How online game addiction scores changed in time}

The mean scores and standard deviations of the scales in 2013 and 2015 was shown in Table 3. Unconditional growth model as only the time was in the model revealed that GAS scores of gamers significantly decreased from 2013 to 2015 ( $\beta=-3.62, S E=1.60, p=0.026)$. SLS, RSES, and MSPSS scores of participants were entered into the model in the second step. The results indicated that only MSPSS scores significantly and negatively associated with GAS scores $(\beta=-0.27$, $\mathrm{SE}=0.08, \mathrm{p}<0.001)$ and the negative association of time remained significant $(\beta=-3.58, \mathrm{SE}=1.66, \mathrm{p}=0.035)$. One unit decrease in MSPSS scores in two years appears to be associated with 0.27 unit increase in GAS scores, even the overall GAS scores decreased in this period. The full model explained $8 \%$ of the total variance in game addiction.

\section{How game addiction rates changed in time}

We also examined how game addiction rates of the participants changed in two-year time. Online game addiction was defined in accordance with both monothetic and polythetic format of 7-item short form of GAS. Accordingly, participants who fulfilled 4 criteria out of 7 -item were accepted as having online game addiction in polythetic format, whereas in monothetic format fulfilling all criteria was required for di- agnosis as it is stated in the original study of Lemmens et al. ${ }^{13}$ $10(9 \%)$ out of 110 participants found to have online game addiction when assessed with monothetic format in 2013. In the follow-up, 7 of these 10 participants were found not to have online game addiction according to monothetic format but were in risky group according to polythetic format. Also two participants reported that they hadn't been playing any online games for at least last 6 months. On the other hand, 2 out of 100 participants, who were accepted as not having online game addiction when assessed with monothetic format in year 2013, were found to have online game addiction in the follow-up. Among rest of the participants, 67 of them were still not having online game addiction and 31 of them were not playing any online games for at least last 6 months (Figure $1 \mathrm{~A})$.

With polythetic format, 50 (45\%) out of 110 participants had online game addiction in 2013. In follow-up, 24 (48\%) out of these 50 gamers were found still to have online game addiction, whereas 16 (32\%) of them didn't have online game addiction. Ten (20\%) participants reported that they were not playing any online games for at least last 6 months. On the other hand, 7 (11.6\%) out of 60 people who did not have online game addiction in 2013 were found to have online game addiction in the follow-up. Thirty (50\%) of them were found not to still have online game addiction and 23 (38.3\%) people reported that they were not playing any online games for at least last 6 months. Change in online game addiction rates from 2013 to 2015 can be seen in Figure 1B.

\section{DISCUSSION}

The results of current study indicate that online game addiction rates of the Travian players, which is diagnosed via using 7-item short form of GAS, changed within two years. According to monothetic format, online number of participants who were diagnosed with online game addiction decreased from $9 \%$ to $2.7 \%$ in two years. On the other hand, according to polythetic format this rate decreased from $45 \%$ to $28.2 \%$. Also, it is found that total GAS scores of the participants decreased significantly within two-year interval indicating a decrease in symptom severity of the players. Our results supports the evidence of temporal instability and tran- 


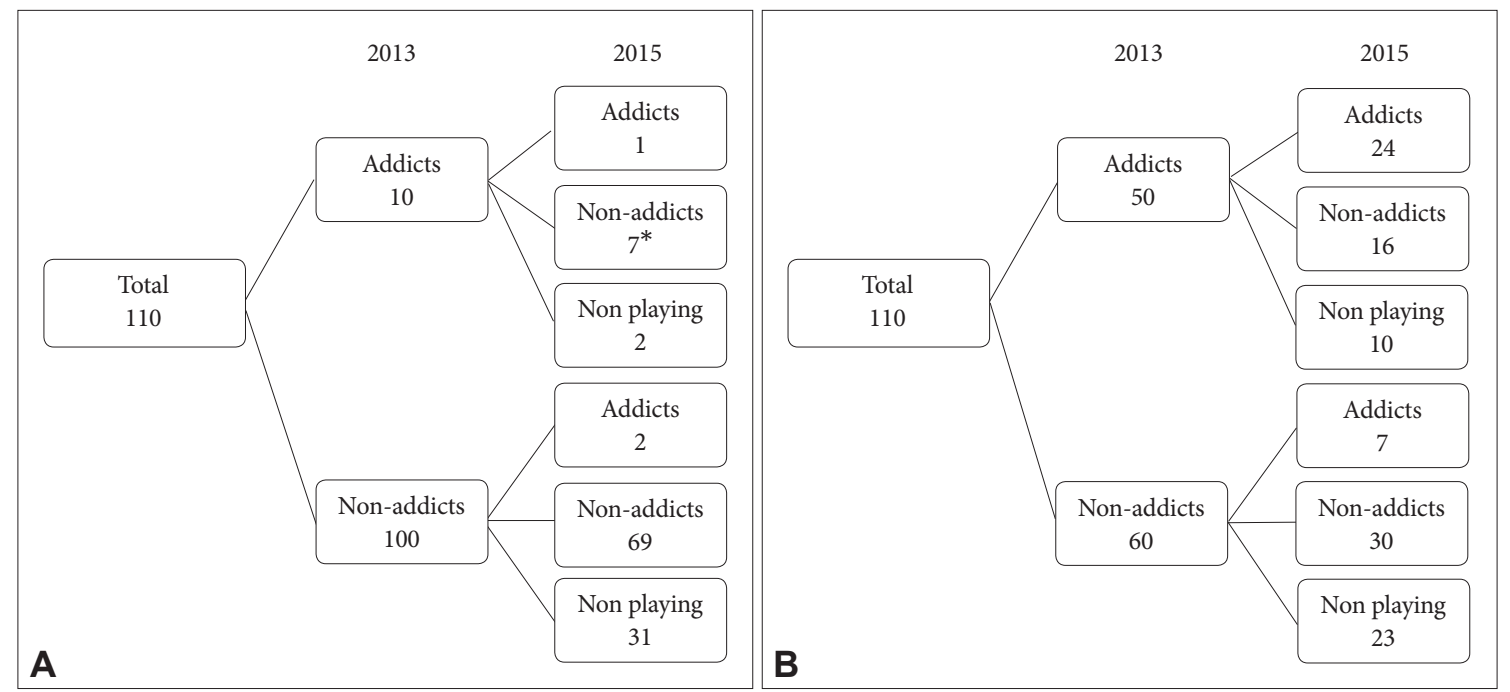

Figure 1. The change in game playing characteristics of participants from 2013 to 2015 according to (A) monothetic format, (B) polythetic format of GAS. *six of these 7 gamers still have game addiction according to polythetic format of GAS. GAS: Game addiction Scale.

sient feature of IGD.

Lack of adequate data regarding temporal stability of IGD is a major problem in IGD research. It is clear that prospective studies that investigate the game addiction rates of online gamers are limited in number. There is a growing number of evidence suggesting that in long term some gamers experience a decline in their problematic gaming symptoms pointing out the unstable pattern of the disorder. Van Rooij et $\mathrm{al}^{28}$ identified two group of gamers, addicted and nonaddicted, via using latent class identification method among their adolescent study sample. They used Compulsive Internet Use Scale to measure problematic gaming and reported that half of the addicted online gamers were still addicted one year later. In their two-year prospective study with children and adolescents, Gentile et al. ${ }^{5}$ reported that $16.4 \%$ of pathological video gamers in their sample had significantly decreased symptoms while the remaining stayed stable and only $1.3 \%$ of non-pathological gamers became pathological gamers within two years. Strittmatter et al. ${ }^{29}$ conducted a three wave longitudinal study to investigate course and stability of not pathological gaming in particular, but pathological internet use (PIU) in general, among German adolescents. The study presented a decreasing and fluctuating prevalence of PIU from $4.3 \%$ at zero time point to $2.7 \%$ (T1) and $3.1 \%$ (T2) over 2-years. Authors indicated the transient nature of PIU during adolescence and discussed the stability of categorical PIU. In another three wave longitudinal study of Scharkow et al., ${ }^{30}$ a large sample with a large age range was investigated for gaming behavior and some psychosocial factors. The authors reported that almost $75 \%$ of the initially problematic users showed a decline in addiction symptoms in a 2-year timespan and underlined the unstable feature of problemat- ic online gaming behavior.

As the syndrome model of addiction indicates, addiction is a syndrome that may have various manifestations including substance and behavioral expressions. ${ }^{31}$ This model suggest that with the interaction and accumulation of certain neurobiological and psychosocial factors, which may be genetic or acquired, people develop predisposition to addiction but the emergence and the type of addiction may depend on which object of addiction the individual encounters with. If the repeated interaction with the object yields certain neurobiological and social consequences altogether with a desirable subjective experience, then the transition to addiction occurs. This broader understanding of addiction may partially explain the temporal instability of IGD. The gamers may develop other addictions such as gambling, shopping, sex/ pornography, and alcohol as a result of exposure to different addictive objects in parallel with their changing life events and experiences. According to this model, the decrease in game addiction rates and symptom severity of participants may be associated with changes in encountered addiction objects in their lives within two year interval.

On the other hand, this decline may also be explained partially with adaptation model of Shaffer and his colleagues in pathological gambling. ${ }^{32}$ The proposed model suggest that similar to spread of infectious diseases, where case rates decline after the initial exposure to infectious agent, the prevalence rate of gambling disorders increase at first and after a stabilization period it declines gradually in long-term. Shaffer et al. ${ }^{33}$ argue that gambling is not a progressive disorder, instead shortly after facing new gambling opportunities individuals experience an adaptation process that they adapt to the novelty and risks of exposure to that gambling oppor- 
tunity and change their behaviors in response to that. This behavioral pattern seems to limit the effects of exposure and prevalence rates of gambling. Similar to that, introduction of new online game may lead to the novelty effect where gamers closely involve with that particular game and spend more time in it in short-term, subsequently as they become familiar with the game, the novelty effect fades away resulting a decrease in prevalence rates. When a new online game is released into the market, a huge number of gamers are attracted to it due to its popularity and spend a lot of time in the game, however in the long run playing durations and addiction rates decrease. In accordance with this, as a new server starts in Travian the number of active players rise up to around twenty thousand, subsequently, this number decrease to two or three thousand towards the end of game. We suppose that this fact may explain the decline in online game addiction rate and symptom severity within two years in our study.

Here, we also investigated the association of SLS, RSES, and MSPSS scores of participants with GAS scores and found that only MSPSS scores significantly and negatively associated with GAS scores. Decrease of MSPSS scores within the study interval appears to increase GAS scores of the participants. The relationship between social support and internet addiction was investigated in previous research. Several studies reported a negative relationship between perceived social support and internet addiction among adolescents and young adults $^{34-36}$ showing that adolescents with low social support is under a high risk for internet addiction. Need for getting social support via interacting with online friends is known to contribute to internet gaming addiction among adolescents. ${ }^{37}$ In addition to internet addiction, it was also suggested that deriving in-game social support is an important motivation for online gaming in particular. In-game social support was found to be associated with fewer negative psychological symptoms and increased engagement in the games probably leading to excessive playing. ${ }^{38}$ Hyun et al. ${ }^{39}$ reported that family environment as a social interaction factor is an important risk factor for online gaming addiction. On the other hand, in the longitudinal study of Scharkow et al. ${ }^{30}$ perceived social support was reported to be negatively correlated with GAS scores of only adolescents and young adults in the first assessment. However, the authors indicated that they did not find a longitudinal interdependence of problematic gaming and perceived social support in any age. Our results seems to be in line with literature as it indicates a negative relationship between social support and game addiction.

On the other hand, we didn't find a relationship between the scores of GAS and SLS and RSES. There are some studies that point out a possible relationship between decreased self-esteem and gaming addiction ${ }^{17,39}$ beside the studies that found no relationship. ${ }^{39}$ Similar to that, a possible relationship was shown between decreased life satisfaction and gaming addiction ${ }^{20}$ whereas some studies mentioned that there was no link..$^{40}$

There are some limitations in this study that should be noted. Firstly, the vast majority of the 726 Travian players did not reply to second invitation for participation to the study, because e-mail addresses of the participants were temporary addresses that were signed up for Travian in particular. Second, due to limited number of participants we did not investigate the relationship between socio-demographic variables and psychosocial factors, and change in gaming behavior. Third limitation is the two-year interval between two assessments which may be too long for follow-up. The fourth limitation is assessing the participants via self-report scales but not via face-to-face clinical evaluation. This limitation led us determine the game addiction levels of the participants merely based on their subjective experiences and may decreased the validity of the possible presence of IGD among subjects. As being online, this study shares the common disadvantages of online research such as limited sampling and respondent availability and possible cooperation problems. Lastly, due to large age range of the participants, certain developmental stages and features of the participants might have emerged as confounding variables.

In conclusion, we think that online game addiction is a topic that few studies have been conducted compared to the size of the problem and prospective studies are particularly limited in literature. This study is worthy as it indicates the change in online gaming behavior within two years. As far as we know, this is the first prospective study from Turkey that is conducted among online gamers. The study also presents limited but significant data regarding risk factors of pathological online gaming. The low participation rate in follow-up study probably led us to diagnose insufficient number of game addicts according to monothetic and polythetic format. Therefore, we suggest for future studies to take necessary precautions to increase participation to follow-up assessments.

\section{REFERENCES}

1. American Psychiatric Association. Diagnostic and Statistical Manual of Mental Disorders (DSM- $5^{\mathbb{B}}$ ). Washington, DC: American Psychiatric Pub; 2013.

2. Hussain Z, Griffiths MD, Baguley T. Online gaming addiction: Classification, prediction and associated risk factors. Addict Res Theory 2012;20:359-371.

3. Starcevic V. Internet gaming disorder: inadequate diagnostic criteria wrapped in a constraining conceptual model. Commentary on: Chaos and confusion in DSM-5 diagnosis of Internet Gaming Disorder: Issues, concerns, and recommendations for clarity in the field (Kuss et al.). J Behav Addict 2017;6:110-113.

4. Griffiths MD. The role of context in online gaming excess and addic- 
tion: Some case study evidence. Int J Ment Health Addict 2010;8:119125 .

5. Gentile DA, Choo H, Liau A, Sim T, Li D, Fung D, et al. Pathological video game use among youths: a two-year longitudinal study. Pediatrics 2011;127:e319-e329.

6. Online gaming increases worldwide, with trends toward social and mobile games. Available at: https://www.ystats.com/online-gaming-increases-worldwide-with-trends-toward-social-and-mobile-games-2/. Accessed October 17, 2017.

7. Key facts and insights on Cross-Screen Monetization of Games in Europe and the US. Available at: https://newzoo.com/wp-content/uploads/2011/06/Newzoo_Free_Global_Trend_Report_2012_2016_V2.pdf. Accessed October 17, 2017.

8. Bozoglan B, Demirer V, Sahin I. Problematic internet use: Functions of use, cognitive absorption, and depression. Comput Hum Behav 2014; 37:117-123.

9. Odacı H, Çelik ÇB. Who are problematic internet users? An investigation of the correlations between problematic internet use and shyness, loneliness, narcissism, aggression and self-perception. Comput Human Behav 2013;29:2382-2387.

10. Şenormancı Ö, Saraçlı Ö, Atasoy N, Şenormancı G, Koktürk F, Atik L. Relationship of internet addiction with cognitive style, personality, and depression in university students. Compr Psychiatry 2014;55:1385-1390.

11. Dindar M, Akbulut Y. Motivational characteristics of Turkish MMORPG players. Comput Hum Behav 2014;33:119-125.

12. Dindar M, Akbulut Y. Role of self-efficacy and social appearance anxiety on gaming motivations of MMOFPS players. Comput Educ 2015; 81:26-34.

13. Lemmens JS, Valkenburg PM, Peter J. Development and validation of a game addiction scale for adolescents. Med Psychol 2009;12:77-95.

14. Baysak E, Kaya FD, Dalgar I, Candansayar S. Online game addiction in a sample from Turkey: Development and validation of the Turkish version of game addiction scale. Klinik Psikofarmakoloji Bülteni Bull Clin Psychopharmacol 2016;26:21-31.

15. Baysak E, Kaya FD, Dalgar İ, Şahiner IV, Candansayar S. Who Plays Online Games? Demographic Information from A Turkish Sample. . XVII World Congress of Psychiatry. Taiwan; 2015.

16. Charlton JP, Danforth ID. Distinguishing addiction and high engagement in the context of online game playing. Comput Hum Behav 2007; 23:1531-1548.

17. Beard CL, Haas AL, Wickham RE, Stavropoulos V. Age of initiation and Internet gaming disorder: the role of self-esteem. Cyberpsychol Behav Soc Netw 2017;20:397-401.

18. Park JH, Han DH, Kim BN, Cheong JH, Lee YS. Correlations among social anxiety, self-esteem, impulsivity, and game genre in patients with problematic online game playing. Psychiatry investig 2016;13:297-304.

19. Wartberg L, Kriston L, Kammerl R. Associations of social support, friends only known through the internet, and health-related quality of life with internet gaming disorder in adolescence. Cyberpsychol Behav Soc Netw 2017;20:436-441.

20. Bargeron AH, Hormes JM. Psychosocial correlates of internet gaming disorder: Psychopathology, life satisfaction, and impulsivity. Comput Hum Behav 2017;68:388-394.

21. Yee N. Motivations for play in online games. Cyberpsychol Behav 2006; 9:772-775

22. Diener E, Emmons RA, Larsen RJ, Griffin S. The satisfaction with life scale. J Pers Assess 1985;49:71-75.

23. Köker S. Comparison of Life Satisfaction Levels of Normal and Problematic Adolescents. Ankara: The Graduate School of Social Sciences. Ankara University; 1991.

24. Çuhadaroğlu F. Self-esteem in Adolescents. Psychiatry. Ankara: Hacettepe University; 1986.

25. Zimet GD, Dahlem NW, Zimet SG, Farley GK. The multidimensional scale of perceived social support. J Pers Assess 1988;52:30-41.

26. Eker D, Arkar H, Yaldız H. Factorial structure, validity, and reliability of revised form of the multidimensional scale of perceived social support. Turk J Psychiatry 2001;12:17-25.

27. Raudenbush SW, Bryk AS, Cheong YF, Congdon R, Du Toit M. Hierarchical Linear and Nonlinear Modeling (HLM7). Lincolnwood, IL: Scientific Software International, Inc.; 2011.

28. Van Rooij AJ, Schoenmakers TM, Van de Eijnden RJ, Van de Mheen D. Compulsive internet use: the role of online gaming and other internet applications. J Adolesc Health 2010;47:51-57.

29. Strittmatter E, Parzer P, Brunner R, Fischer G, Durkee T, Carli V, et al. A 2-year longitudinal study of prospective predictors of pathological internet use in adolescents. Eur Child Adolesc Psychiatry 2016;25:725734 .

30. Scharkow M, Festl R, Quandt T. Longitudinal patterns of problematic computer game use among adolescents and adults- A 2-year panel study. Addiction 2014;109:1910-1917.

31. Shaffer HJ, LaPlante DA, LaBrie RA, Kidman RC, Donato AN, Stanton MV. Toward a syndrome model of addiction: Multiple expressions, common etiology. Harv Rev Psychiatry 2004;12:367-374.

32. LaPlante DA, Shaffer HJ. Understanding the influence of gambling opportunities: expanding exposure models to include adaptation. Am J Orthopsychiatry 2007;77:616-623.

33. Shaffer H, Vander Bilt J, Hall MN. Estimating the Prevalence of Disordered Gambling Behavior in the United States and Canada: A metaanalysis. Boston, MA: Harvard Medical School; 1997.

34. Chen X, Li FH, Long LL. Prospective study on the relationship on between social support and internet addiction. Chin Ment Health J 2007;21:240-243.

35. Gunuc S, Dogan A. The relationships between Turkish adolescents' internet addiction, their perceived social support and family activities. Comput Hum Behav 2013;29:2197-2207.

36. Naseri L, Mohamadi J, Sayehmiri K, Azizpoor Y. Perceived social support, self-esteem, and internet addiction among students of Al-Zahra University, Tehran, Iran. Iran J Psychiatry Behav Sci 2015;9:e421.

37. Wu JY, Ko HC, Wong TY, Wu LA, Oei TP. Positive outcome expectancy mediates the relationship between peer influence and Internet gaming addiction among adolescents in Taiwan. Cyberpsychol Behav Soc Netw 2016;19:49-55.

38. Longman $\mathrm{H}$, O'Connor E, Obst P. The effect of social support derived from World of Warcraft on negative psychological symptoms. Cyberpsychol Behav 2009;12:563-566.

39. Hyun GJ, Han DH, Lee YS, Kang KD, Yoo SK, Chung US, et al. Risk factors associated with online game addiction: a hierarchical model. Comput Hum Behav 2015;48:706-713.

40. Sarda E, Begue L, Bry C, Gentile D. Internet gaming disorder and wellbeing: a scale validation. Cyberpsychol Behav Soc Netw 2016;19:674679 . 